\title{
La educación superior en Colombia y el olvido por la pregunta del ser
}

Zl tema de la educación en Colombia produce múltiples sensacio-

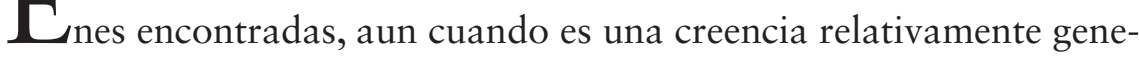
ralizada que educarse es necesario para conseguir empleo y con ello calidad de vida. Encontrar una educación de calidad y accesible para todo el que aspire a ella se ha convertido en una tarea complicada, ya que no todas las personas cuentan con los medios económicos para poder pagar su educación o la de sus hijos y las universidades públicas no cuentan con los cupos necesarios para solucionar la situación.

Como mencionaba, hay una idea generalizada en la que la educación está asociada a la calidad de vida: "Estudie para que sea alguien en la vida" ha sido una frase utilizada por algunos padres con sus hijos; sin embargo, cabría preguntarse ¿qué significa ser alguien?, ¿cómo saber que una persona tiene calidad de vida por medio de la educación?, ¿el dinero tiene un papel protagónico en este tipo de frases?, ¿cuál es el sentido de la educación y en específico de la educación superior?, ¿cuál es el propósito de la universidad en la vida de un estudiante?

Si bien la universidad es el templo de construcción e intercambio de conocimiento, las preguntas anteriores remiten a lo humano, al desarrollo como persona. ¿De qué manera las universidades preparan a sus estudiantes para resolver conflictos, para intercambiar ideas y respetar puntos de vista, para la convivencia con otros, para 
escucharse a sí mismos y entender que sus dilemas son importantes y que tienen derecho a resolverlos, para establecer contacto con sus emociones y aprender a manejarlas, para tener visión de género, para ser honestos, respetuosos y dejar de lado las respuestas violentas? Una gran pregunta que algunas universidades y el Gobierno nacional han comenzado a hacerse, pero a la cual no se le ha dado la importancia que merece.

Algunas universidades han comenzado a implementar cátedras que apuntan al desarrollo humano dentro de sus currículos, sin embargo, estas pueden ser tratadas como las famosas materias de "relleno" y se trabajan en algún semestre aislado, se descuida la continuidad en el proceso de desarrollo humano del estudiante y carecen de importancia en comparación con los conocimientos de tipo científico.

\section{La estructura de la educación en Colombia}

En ese olvido por el ser se encuentra la educación en Colombia. Aunque hay un acercamiento a resolver la necesidad de desarrollo humano, aún falta camino por recorrer para alcanzar la tan mencionada y anhelada educación integral. Ese interés por no descuidar la formación como personas se encuentra inmerso en la Ley 30 de 1992 que regula la educación superior y la define como "un proceso permanente que posibilita el desarrollo de las potencialidades del ser humano de una manera integral"; mas no aclara ni profundiza qué implica la educación integral, y posteriormente agrega:

Cada campo del saber, despertará en los educandos un espíritu reflexivo, orientado al logro de la autonomía personal, en un marco de libertad de pensamiento y de pluralismo ideológico que tenga en cuenta la universalidad de los saberes y la particularidad de las formas culturales existentes en el país. Por ello, la Educación Superior se desarrollará en un marco de libertades de enseñanza, de aprendizaje, de investigación y de cátedra (Ley 30 de 1992). 
Este artículo hace referencia a la libertad y pluralidad e ideologías teniendo como base un contexto académico, pero no hay referencias al desarrollo del ser. En el capítulo 3, la Ley 30 hace referencia al departamento de bienestar universitario, el cual se encargará de realizar programas y actividades que propendan por el desarrollo físico, psicoafectivo, espiritual y social de la comunidad universitaria en general, por lo que en este punto hay un énfasis en el desarrollo de la persona. Sin embargo, este capítulo está compuesto por otros dos artículos además del mencionado; el siguiente habla del presupuesto que se le debe destinar a bienestar universitario y el último trata sobre la garantía por parte de la universidad de escenarios deportivos para la comunidad universitaria.

Al hacer esta revisión de la ley, se puede notar que partiendo desde la instancia macro -el Gobierno colombiano y el Ministerio de Educación- no hay una mayor preocupación por el ser, por la verdadera formación integral, aunque hay un inicio: la creación de los departamentos de bienestar universitario, frente a los cuales Misas (2004) plantea una idea para analizar: "La formación planteada en este documento solo es posible lograrla si se cuenta con estudiantes motivados, interesados en acrecentar sus conocimientos, con capacidades de apropiarse el discurso de la ciencia a lo largo de la formación del pregrado y de contribuir a desarrollarlo a través de los estudios de posgrado".

Lo llamativo de la idea del autor es que al hablar de bienestar universitario propone que uno de los sentidos de este es motivar a los estudiantes, preocuparse por su bienestar, pero en su texto pareciera que el lado humano le sirve al conocimiento académico, es decir, es su fin, su propósito, que el estudiante se sienta bien para poder aprender, lo cual puede tener sentido, pero deja al desarrollo humano en un lugar secundario, saca a relucir que en la universidad el objetivo primario es el conocimiento y no la formación.

Con esta idea de base sobre la educación se puede ahora revisar de manera breve el modo de organización de la educación superior en Colombia. 


\section{Campos, niveles e Instituciones de Educación Superior}

Los campos de acción definidos por la educación superior en Colombia son: la técnica, la ciencia, la tecnología, las humanidades, el arte y la filosofía (Ley 30 de 1992). Los programas académicos deben estar inscritos en estos campos y pueden desarrollarse en niveles de pregrado y posgrado.

Los programas de pregrado preparan para el desempeño de ocupaciones, para el ejercicio de una profesión o disciplina determinada, mientras que los programas de posgrado, denominados como especializaciones, son aquellos que se desarrollan con posterioridad a un programa de pregrado y posibilitan el perfeccionamiento en la misma ocupación, profesión, disciplina o áreas afines o complementarias. Los demás posgrados, como maestría, doctorado y posdoctorado basan su quehacer en la investigación como fundamento; para acceder al doctorado no es necesario cursar la maestría.

En lo referente a los centros de formación, son instituciones universitarias o escuelas tecnológicas aquellas facultadas para adelantar programas de formación en ocupaciones, programas de formación académica en profesiones o disciplinas y programas de especialización (Ley 30 de 1992).

Son universidades las reconocidas actualmente como tales y las instituciones que acrediten su desempeño con criterio de universalidad en las siguientes actividades: investigación científica o tecnológica; formación académica en profesiones o disciplinas, y la producción, desarrollo y transmisión del conocimiento y de la cultura universal y nacional (Ley 30 de 1992). Estas instituciones están igualmente facultadas para adelantar programas de formación en ocupaciones, profesiones o disciplinas, programas de especialización, maestrías, doctorados y posdoctorados, de conformidad con la ley.

\section{La educación por ciclos y por créditos}

Desde hace algunos años el sistema educativo colombiano ha venido transformándose para responder no solo a las necesidades de formación integral, sino a las necesidades globales y posibilitarle a los 
profesionales colombianos ejercer sus carreras en otros países haciendo uso de la homologación o permitir el cambio de universidad durante el periodo de estudio y que, de esta manera, el estudio realizado sea válido en otros países, ciudades o universidades. Para poder lograr este objetivo ha sido necesario recurrir a la flexibilidad curricular y plantear la educación por ciclos y por créditos.

Según el MEN (2009), los ciclos son unidades interdependientes, complementarias y secuenciales que se constituyen como una fase en la educación que le permiten al estudiante desarrollarse en su formación profesional teniendo en cuenta sus habilidades e intereses. Este tipo de formación le facilita al estudiante transitar de la educación técnica a la tecnológica y luego a la profesional. Para que esto sea posible se hace necesario que el alumno, en su primer ciclo de formación, vea asignaturas correspondientes al nivel técnico; el segundo ciclo tiene que ver con el nivel tecnológico, por lo que apunta a responsabilidades de concepción, dirección y gestión; y el último ciclo se enfoca en lo profesional y apunta a que la persona asuma el ejercicio autónomo de actividades profesionales y domine conocimientos técnicos y científicos.

En este sistema, el estudiante es libre de escoger libremente su carrera técnica, tecnológica o profesional así como de darle continuidad a su estudio o detenerse en el nivel que desee; además, cada ciclo ofrece la posibilidad de realizar una especialización.

Gracias a la educación por ciclos, las Instituciones de Educación Superior tienen la posibilidad de organizar sus programas en forma coherente y coordinada, similar a una cadena formada por eslabones y, a la vez, articular sus programas con las necesidades del mundo laboral, enriqueciendo la formación de la persona en conexión con el contexto en el que se desenvuelve y se desenvolverá.

Los créditos académicos también hacen parte de la flexibilidad curricular y son las unidades que miden el tiempo estimado de actividad académica del estudiante en función de las competencias académicas y profesionales que se esperan que el programa desarrolle (MEN, 2011). Un crédito equivale a 48 horas totales de trabajo del estudiante, incluidas las horas de acompañamiento docente y las horas que deba destinar a actividades diferentes a las del aula de clase y que 
estén relacionadas con la asignatura cursada. Las únicas horas que no se incluyen son las destinadas a presentación de exámenes finales.

Por lo general, la estructura de las asignaturas implica que por cada hora de clase haya dos horas de trabajo fuera del aula en pregrado y tres horas en posgrado. La relación real dependerá de las características de la materia y de la metodología empleada por la institución educativa; por ejemplo, hay asignaturas que requieren de la presencia del docente, pero no de trabajo independiente por parte del estudiante.

El sistema de educación por créditos facilita no solo la formación del estudiante en actividades autónomas, sino que también posibilita —al igual que la formación por ciclos— la homologación entre universidades y la convalidación de títulos del extranjero, ya que la mayoría de países del mundo utiliza los créditos académicos en la educación superior.

\section{Sobre el sistema de calidad en la educación}

En Colombia se han creado el Sistema de Aseguramiento de la Calidad de la Educación Superior, el cual está conformado por los organismos, las acciones y las estrategias que aplican desde el proceso mismo de creación y establecimiento de una institución de educación superior, hasta el desempeño del profesional que egresa del sistema, esto con el fin de brindar garantías en los temas de evaluación, certificación y acreditación de la calidad de la educación superior.

Hay, entonces, dos formas de aseguramiento de la calidad: la primera es el registro calificado, que es otorgado por la Comisión Nacional para el Aseguramiento de la Calidad de la Educación Superior (Conaces) y certifica que un programa académico cuenta con las condiciones básicas o mínimas de calidad para poder funcionar. El Ministerio de Educación Nacional junto con la comunidad académica determinan cuáles son esas características básicas comunes a todos los programas de la misma área del saber (Ley 30 de 1992).

La otra manera es la acreditación de alta calidad, otorgada por el Consejo Nacional de Acreditación (CNA); al igual que en el caso del registro calificado, se han fijado unas características para que un programa pueda obtener la acreditación, sin embargo, esta no es obligatoria, 
cada universidad y cada carrera elige si es su deseo obtenerla y, de ser así, inicia el proceso son el CNA (Ley 30 de 1992).

\section{Cobertura en educación}

Melo, Ramos y Fernández (2014) mencionan que la tasa de cobertura ha aumentado de manera acelerada durante los últimos veinte años en comparación a otras décadas, en el año 2000 fue de $24 \%$ y a finales de 2012 fue de $42.4 \%$. Esta cobertura viene acompañada de la expansión de cupos para las carreras técnicas y tecnológicas. Estas tasas varían dependiendo de la región, siendo Bogotá la que mayor cobertura tuvo al año 2009 con una tasa bruta de $79.6 \%$ y la que menos reportó fue Chocó con una tasa bruta de $5.3 \%$ en el mismo año.

\section{Instituciones}

En el año 2012 Colombia contaba con 288 instituciones, de las cuales 81 son universidades, 120 son instituciones universitarias, 50 instituciones tecnológicas y 37 instituciones técnicas. De ese total 61 son oficiales, 208 privadas y 19 de régimen especial, acorde con los datos presentados por Melo, Ramos y Fernández (2014). En ese mismo año se ofrecieron 5834 programas de formación. De ese total de programas solo $798(8.1 \%)$ cuentan con acreditación de alta calidad: 23 corresponden al nivel técnico profesional, 63 al tecnológico, 677 al universitario y 35 a los posgrados (2 especializaciones, 26 maestrías y 7 doctorados).

\section{¿Y el ser en la educación superior?}

Dentro de la estructura de la educación poco se habla de la formación integral, de la formación de seres humano, o de la formación del ser; sin embargo, la educación por competencias trabaja esta dimensión junto con otras más, aunque cabe preguntarse qué tanto se están trabajando las competencias en los niveles universitario, tecnológico y técnico. 
Según varios autores la formación humana debe ser tarea prioritaria de las universidades y uno de sus objetivos; para Alonso y otros autores (2007) la misión de estas instituciones es propender por la persona responsable y contribuir a la formación de los adolescentes, además de identificar factores de riesgo y de protección desde etapas tempranas de la universidad. Herrán (2004) agrega que la universidad debería favorecer y velar por la madurez personal de los jóvenes, centrarse en la conciencia y superar egocentrismos tanto personales como colectivos y de esta manera contribuir a que la sociedad evolucione, no solo a que avance.

Aunque algunos autores lo mencionen, hagan énfasis e insistan en que la educación debe ser integral y apoyar al desarrollo humano, mucha universidad y sus respectivos programas académicos aún no tienen clara la importancia y la necesidad de poner en práctica estrategias de formación humana, incluso cuando tienen que ver con el problema de la deserción, el cual se trabajará más adelante.

Queda entonces pendiente que las universidades se preocupen más por la formación humana de los estudiantes, haciendo uso de estrategias como la arteterapia para la introspección y el desarrollo del ser, en un presente donde la educación superior cada vez prolifera más y en donde los antivalores hacen presencia. Basta con revisar la situación de algunas universidades e instituciones universitarias que están siendo investigadas por falta de cumplimiento en los requisitos o por malos manejos, por lo que cabría preguntarse ¿qué clase de educación recibieron las directivas de estas universidades? 